\title{
Yüksek Sıcaklıklara Maruz Kalan Kalkarenitlerin Fiziksel ve Dayanım Özelliklerindeki Değişimin Araştırılması
}

\author{
Investigation on the Change of Physical and Strength Properties of Calcarenite Exposed to \\ High Temperatures

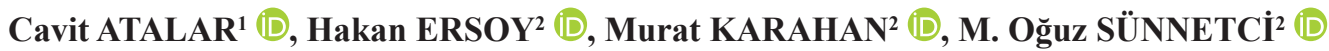 \\ ${ }^{1}$ Yakın Doğu Üniversitesi, Petrol ve Doğal Gaz Mühendisliği Bölümü, KKTC \\ ${ }^{2}$ Karadeniz Teknik Üniversitesi, Jeoloji Mühendisliği Bölümü, 61080, Trabzon
}

Geliş (Received):30 Mart (March) 2020 / Düzeltme (Revised): 06 Ağustos (August) 2020 / Kabul (Accepted): 15 Ağustos (August) 2020

\section{ÖZ}

Bu çalışmada Kuzey Kıbrıs Türk Cumhuriyeti'nde yapı taşı olarak yaygın şekilde kullanılan kalkarenitlerin $200-1000^{\circ} \mathrm{C}$ arasındaki yüksek sıcaklıklara tabi tutulduktan sonraki indeks ve dayanım özelliklerindeki değişimler incelenmiş, elektron mikroskop görüntülerinden yararlanarak yüksek sıcaklıkların mikro yapı üzerindeki etkisi araştırılmıştır. Gerçek bir yangının temsil edilmesi amacıyla örnekler Eurocode tarafından önerilen sıcaklık-zaman eğrilerine ait değerler kullanılarak isıtılmış, hedeflenen sıcaklıkta 2 saat bekletildikten sonra oda sıcaklığında soğumaya bırakılmıştır. Yapılan deneysel çalışmalar sonrasında ilk $600^{\circ} \mathrm{C}$ 'ye kadar yoğunluk ve ağırlık kaybı değerlerinde belirgin bir değişim olmadığ 1 görülmüştür. $600^{\circ} \mathrm{C}$ 'den sonra yoğunlukta ani bir azalma kaydedilmiş, $1000^{\circ} \mathrm{C}$ sıcaklıklarda mikro-kırıklara bağlı olarak yoğunluk 1'in altına düşmüştür. Aynı şekilde ağırlık kaybı değeri kalsitlerde görülen kalsinasyon sürecine bağlı olarak \%41'e ulaşmıştır. P-dalga hızı ve çekme dayanımı değerleri sıcaklığa bağlı olarak sürekli azalmıştır. Ancak bu azalma $600^{\circ} \mathrm{C}$ 'den sonra daha belirgin olurken $800^{\circ} \mathrm{C}$ 'den sonra en belirgin düzeye ulaşmıştır. SEM görüntülerinde yapılan incelemelerde de özellikle $600^{\circ} \mathrm{C}$ 'den sonra gelişen topaklaşmaya bağlı olarak süreksizlik oluşumu gözlenmiştir. Bu durum dayanımdaki azalmanın asıl nedeni olarak görülmektedir. Eurocode tarafından uygulanan deneysel çalışmalarda bina dışında meydana gelecek bir yangının sıcaklığının $680^{\circ} \mathrm{C}$ 'yi geçmeyeceği, iç mekânda meydana gelecek bir yangında ise sıcaklığın $1000^{\circ} \mathrm{C}$ 'yi aşabileceği belirtilmektedir. Bu nedenle çalışma konusu kalkarenitlerin yapılarda sadece dış kaplama olarak kullanılması önerilmektedir.

Anahtar Kelimeler: Dayanım, Kalkarenit, SEM, Yangın, Yüksek Sıcaklık, KKTC

\section{ABSTRACT}

In this study, the changes in the index and strength properties of calcarenites, which are widely used as building stone in the Turkish Republic of Northern Cyprus, after being subjected to high temperatures between 200 and $1000^{\circ} \mathrm{C}$, and the effects of high temperatures on microstructure of the calcarenite were investigated by using electron microscope images. In order to represent a real fire incident, the samples were heated using the temperature-time curves recommended by Eurocode, and left to cool at room temperature after 2 hours of exposure at target temperature. After the experimental studies, it was observed that there was no significant change in density and weight loss values up to $600^{\circ} \mathrm{C}$. After $600^{\circ} \mathrm{C}$, a sudden decrease in density was recorded, at $1000^{\circ} \mathrm{C}$ the density dropped below 1 due to 
Atalar, Ersoy, Karahan, Sünnetci

microcracks. Likewise, the weight loss value reached $41 \%$ depending on the calcination process observed in calcites. $P$-wave velocity and tensile strength values decreased continuously depending on the temperature. However, this decrease became more pronounced after $600^{\circ} \mathrm{C}$ and reached the most prominent level after $800^{\circ} \mathrm{C}$. In SEM images, discontinuity formation was observed due to the agglomeration that developed especially after $600{ }^{\circ} \mathrm{C}$. This situation is considered as the main reason for the decrease in strength. In experimental studies applied by Eurocode, it is stated that the temperature of a fire that will occur outside the building will not exceed $680^{\circ} \mathrm{C}$, and in a fire that will occur indoors, the temperature will exceed $1000^{\circ} \mathrm{C}$. For this reason, it is recommended that calcarenites, which are the subject of the study, are used only as outer coatings in buildings.

Keywords: Strength, Calcarenite, SEM, Fire, High Temperature, KKTC

\section{GİRIŞ}

Yüksek dayanımlı kayaçlar bile ıslanmakuruma, donma-çözülme, yüksek sıcaklık ve asit yağmurları gibi çevresel olayların etkisinde kalabilir ve bu durumda dayanımlarını büyük oranda kaybederler. Özellikle yangın gibi yüksek sıcaklıkların etkisinde karbonat kayaçların dayanımlarının $\% 90$ oranında azalabildiği bilinmektedir. $\mathrm{Bu}$ nedenle son yıllarda yüksek sıcaklıklar etkisinde kalan karbonat kayaçların fiziksel, dayanım ve mineralojik özelliklerindeki değişimlerinin araştırıldığı birçok çalışma yapılmıştır (Brotons vd., 2013: Özgüven ve Özçelik, 2013: Zang vd., 2015: Crosby vd., 2018: Yang vd., 2019: Meng vd., 2020).

Zang vd. (2015) tarafindan yapilan çalışmalarda boyuna dalga hızı ve dayanım değerlerinin $300^{\circ} \mathrm{C}$ 'ye kadar hafif olarak azaldığ $\breve{g}_{1} \quad 300-600^{\circ} \mathrm{C}$ arasında azalmanın çok belirgin olduğunu, $600^{\circ} \mathrm{C}^{\prime}$ den sonra bu belirginliğin azaldığını ortaya koymuşlardır. Özgüven ve Özçelik (2013) tarafindan yapılan çalışmada, $1000^{\circ} \mathrm{C}$ 'ye kadar 1sıtıldıktan sonra oda sıcaklığında 30 gün süre ile soğumaya bırakılan kireçtaşlarında bozunmanın 10 . günden sonra belirginleştiği belirlenmiştir. Kılıç (2006) tarafindan yapılan çalışmada ise $1050^{\circ} \mathrm{C}$ sicaklığa kadar 1sıtılan kireçtaşlarının boyuna dalga hızı değerlerinin sürekli azaldığı, ağırlık kaybı değerlerinin ise $800^{\circ} \mathrm{C}$ 'de $\% 45$ değerine ulaştığı ortaya koyulmuştur.
Yüksek sıcaklıklar etkisinde kireçtaşlarının mekanik özelliklerindeki değişimlere odaklanan çalışmalarda mevcuttur. Birçok çalışmada tek eksenli sıkışma dayanımı, çekme dayanımı ve elastisite modülü gibi dayanım özelliklerinin $300-400^{\circ} \mathrm{C}$ 'ye kadar yaklaşık sabit kaldığ 1 , bu s1caklıktan sonra ise belirgin bir azalmanın olduğu belirtilmiştir (Brotons vd., 2013; Sengün 2014; Özgüven ve Özçelik, 2014). Brotons vd. (2013) tarafından yapılan çalışmada yüksek sıcaklığa maruz bırakılan kireçtaşları ayrıca hem oda sıcaklığında hem de su içerisine bırakılarak soğutulmuş, suda soğutulan örneklerde daha düşük dayanım değerleri kaydedilmiştir.

Tortul kayaçlar üzerine yapılan çalışmalar genel olarak belli sürelerde isitılan örneklerin soğuma sonrası fiziksel ve dayanım özelliklerindeki değişimler üzerine odaklansa da farklı maruz kalma sürelerinin etkilerinin değerlendirildiği sınırlı sayıda çalışma da mevcuttur (Yavuz vd., 2010; Sirdesai vd., 2017). Yavuz vd. (2010) tarafından yapılan çalışmada kireçtaşları $500^{\circ} \mathrm{C}$ 'ye kadar 1sıtılmış, örnekler 12-144 saat arasında 5 farklı kademede yüksek sıcaklıklara maruz bırakılmıştır. Çalışmada $300^{\circ} \mathrm{C}$ ve altındaki sıcaklıklar için maruz kalma süresinin önemsiz olduğu, $300^{\circ} \mathrm{C}$ sicaklıktan sonra ise ilk 12 saat içinde fiziksel özelliklerde belirgin bir değişimin olduğu belirlenmiştir.

Yapılan çalışmaların çoğu yüksek sıcaklara maruz kalan kayaçlarda meydana gelen termal 
hasarlara odaklanmaktadır (Wang vd., 2016; Dong vd., 2019). Bu çalışmalarda kayaçlar ani ssınmadan kaynaklanacak termal hasarın önüne geçmek amaciyla yavaşça 1sıttılmakta, 1sınma oranı genellikle $1-10^{\circ} \mathrm{C}$ arasinda tercih edilmekte ve maksimum sicaklık değerleri $600-1000^{\circ} \mathrm{C}$ arasında seçilmektedir. Ayrıca hedef sıcaklıkta sabit 1sınma süreleri genellikle 2-6 saat arasında tutulmakta, kayaçlarda ani soğuma etkisini ortadan kaldırmak için oda sıcaklığında ve/veya fırın içinde yavaşça soğutulmaktadır (Çizelge 1).

Çizelge 1. Yüksek sıcaklıkların kayaçlar üzerindeki etkisinin araştırıldığı çalışmalarda uygulanan yöntemler (Zhang vd., 2014; Sun vd., 2016; Qin vd., 2019; Yang vd., 2019).

Table 1. Procedures performed for in the investigations on the effects of high temperature on rocks (Zhang et al., 2014; Sun et al., 2016; Qin et al., 2019; Yang et al., 2019).

\begin{tabular}{lccc}
\hline Uygulama & Çok & Az & Bu çalışma \\
\hline Isınma şekli & Fırında & Alev ile & Fırında \\
\hline Soğuma şekli & $\begin{array}{c}\text { Fırında veya } \\
\text { oda } \\
\text { sıcaklığında }\end{array}$ & $\begin{array}{c}\text { Sivı nitrojen } \\
\text { ile }\end{array}$ & $\begin{array}{c}\text { Oda } \\
\text { sıcaklığında }\end{array}$ \\
\hline $\begin{array}{l}\text { Isınma oranı } \\
\left({ }^{\circ} \mathrm{C} / \mathrm{m}\right)\end{array}$ & $1-10$ & $\begin{array}{c}\text { Üstel } \\
\text { Logaritmik }\end{array}$ & Üstel \\
\hline $\begin{array}{l}\text { Maruz kalma } \\
\text { süresi (s) }\end{array}$ & $2-6$ & $\begin{array}{c}\text { Farklı } \\
\text { zamanlar }\end{array}$ & 2 \\
\hline $\begin{array}{l}\text { Maksimum } \\
\text { Sıcaklık }\left({ }^{\circ} \mathrm{C}\right)\end{array}$ & $600-1000$ & $\begin{array}{c}\text { Standart } \\
\text { yangın } \\
\text { sicaklığı }\end{array}$ & $\begin{array}{c}\text { Standart } \\
\text { yangın } \\
\text { sicaklığ }\end{array}$ \\
\hline
\end{tabular}

$\mathrm{Bu}$ yavaş 1sınma oranları jeotermal alanlar, nükleer atıkların depolandığı derin jeolojik bariyerler ve derin maden kazı alanları için kabul edilebilir olsa da bir yangın sırasında sıcaklığın artışını simüle etmek için yetersizdir (Koca vd., 2006). Bir yangın sirasında ortam sıcaklığı lineer olarak artmaz, aksine ani şekilde yükselerek 5 dakikada $500^{\circ} \mathrm{C}^{\prime}$ ye, yarım saatin sonunda ise $800^{\circ} \mathrm{C}$ 'ye ulaşabilir. Artış çoğunlukla logaritmik veya üstel olmakla birlikte en yüksek artış oranı ilk 5 dakika içerisinde gerçekleşir. Bu nedenle özellikle kayaçlar üzerinde yangınlardan kaynaklanacak etkilerin araştırılması durumunda 1S1 artış oranı ve maruz kalma süresini doğru olarak tanımlamak gerekir (Biro vd., 2019; Wang vd. 2020).

Kuzey Kıbris Türk Cumhuriyeti'nde geçmişten günümüze kadar hemen hemen her yap1 inşasında doğal yap1 taşları kullanılmış, özellikle kumtaşları ve tebeşirler dış kaplama ve duvar yapımında, jipsler ise dekoratif amaçlı yaygın olarak tercih edilmiştir (Şekil 1a, b ve c). Günümüzde ise bu taşlar birçok yapıda, kolay işlenebilir ve hafif olmaları nedeniyle kaplama taşı olarak tercih edilmektedir (Şekil 1d). Tarihi yapılarda yapılan gözlemlerde, bu kayaçların özellikle donma-çözünme, sslanma-kuruma vb gibi çevresel olaylardan etkilendiği görülmüştür. Bu kayaçların bir yangın sonrasında jeo-mekanik özelliklerindeki değişimlerin araştırıldığı bir çalışma mevcut değildir. Bu nedenle, bu çalışma kapsamında Kuzey Kıbrıs Türk Cumhuriyeti'nde (KKTC) geniş yayılımlar veren yüksek poroziteli ve düşük dayanımlı kalkarenitlerin yüksek sıcaklıklar etkisindeki davranışları incelenmiş, gerçek bir yangın sırasında meydana gelecek ani 1sınma durumunu doğru bir şekilde tanımlayan üstel denklemlerle tanımlanan 1sınma oranları dikkate alınmış ve yangın sonrası kayaçların fiziksel ve dayanım özelliklerindeki değişimler değerlendirilmiştir. 


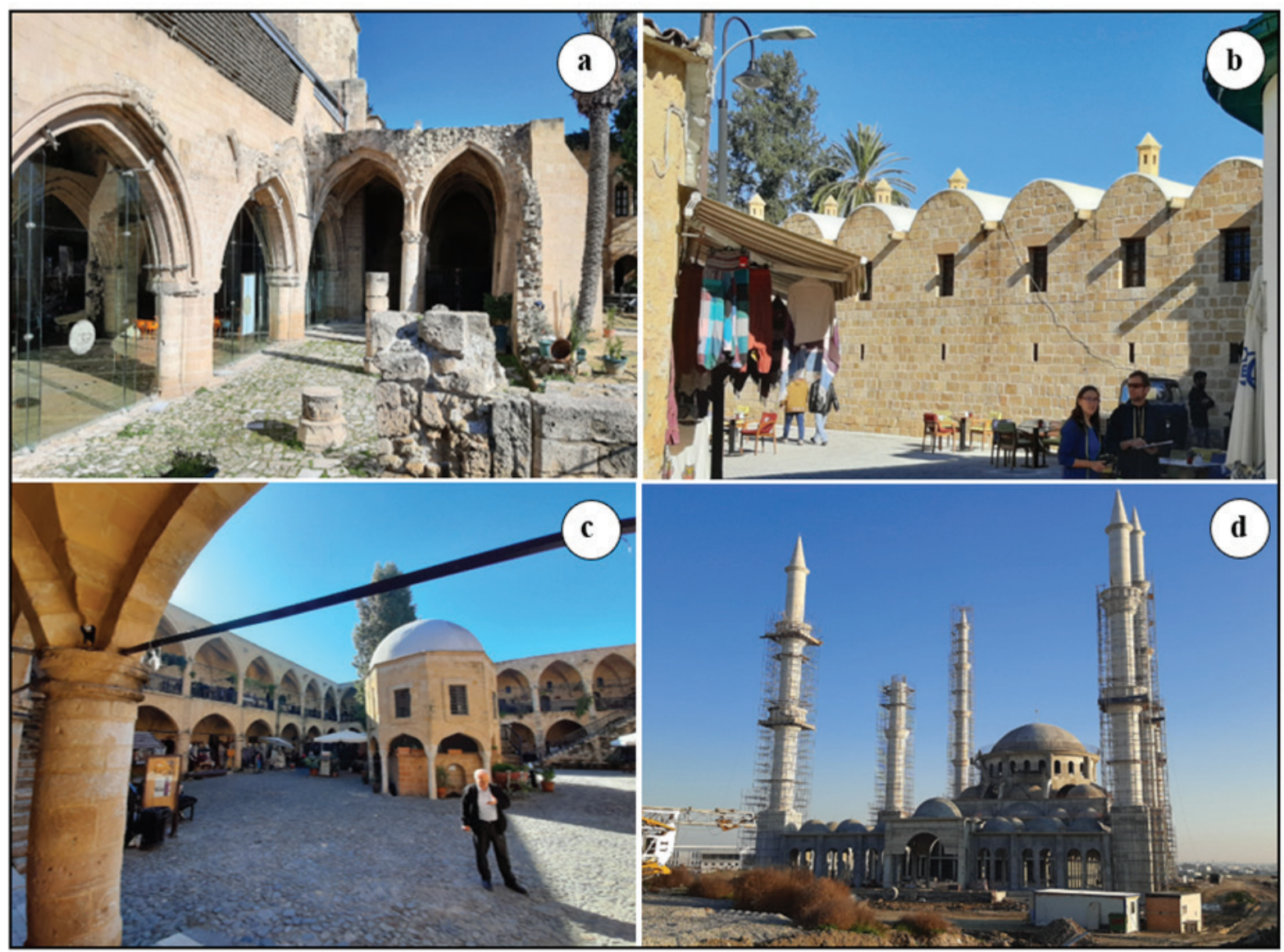

Şekil 1. KKTC'inde kalkarenitler ve tebeşirler kullanılarak inşa edilen tarihi ve güncel yapılar.

Figure 1. Historical buildings built using calcarenites and chalks in the TRNC.

\section{ÇALIŞMA ALANI VE ÇEVRESININN GENEL JEOLOJISI}

Çalışma konusu kayaçlar, Kuzey Kıbrıs Türk Cumhuriyeti'nde geniş yayılımlar veren Üst Pliyosen yaşlı Lefkoşa Formasyonu içerisinde bulunmaktadır (Şekil 2). Lefkoşa Formasyonu az miktarda çakıltaşı ve marn ara katmanı içeren kalın katmanlı kumtaşlarından oluşmaktadır (Hakyemez vd., 2002). Hem kuzeydeki Beşparmak Dağları'ndaki hem de güneydeki Trodos Dağları ve çevresindeki istiflerden türeyen Lefkoşa Formasyonu'nun karbonat kayalarından türeyen kesimleri egemen olarak kalkarenit özelliğindedir. Ancak volkanitlerden, olistostromal birimlerden ve türbiditlerden türeyen kesimleri de kumtaş1 karakterindedir. Çalışma alanından temin edilen örnekler üzerinde yapılan incelemelerde ana bileşenlerin çoğunlukla kireçtaşı ve fosillerden oluşan kayaç kırıntılarından ibaret olduğu belirlenmiştir. Yaklaşık 0.5-1.0 $\mathrm{mm}$ arasında çapa sahip kayaç parçaları tamamen kalsitten oluşan bir çimento ile bağlanmıştır. Bu nedenle çalışma konusu kayaçların kalkarenit olduğu sonucuna varılmıştır. 


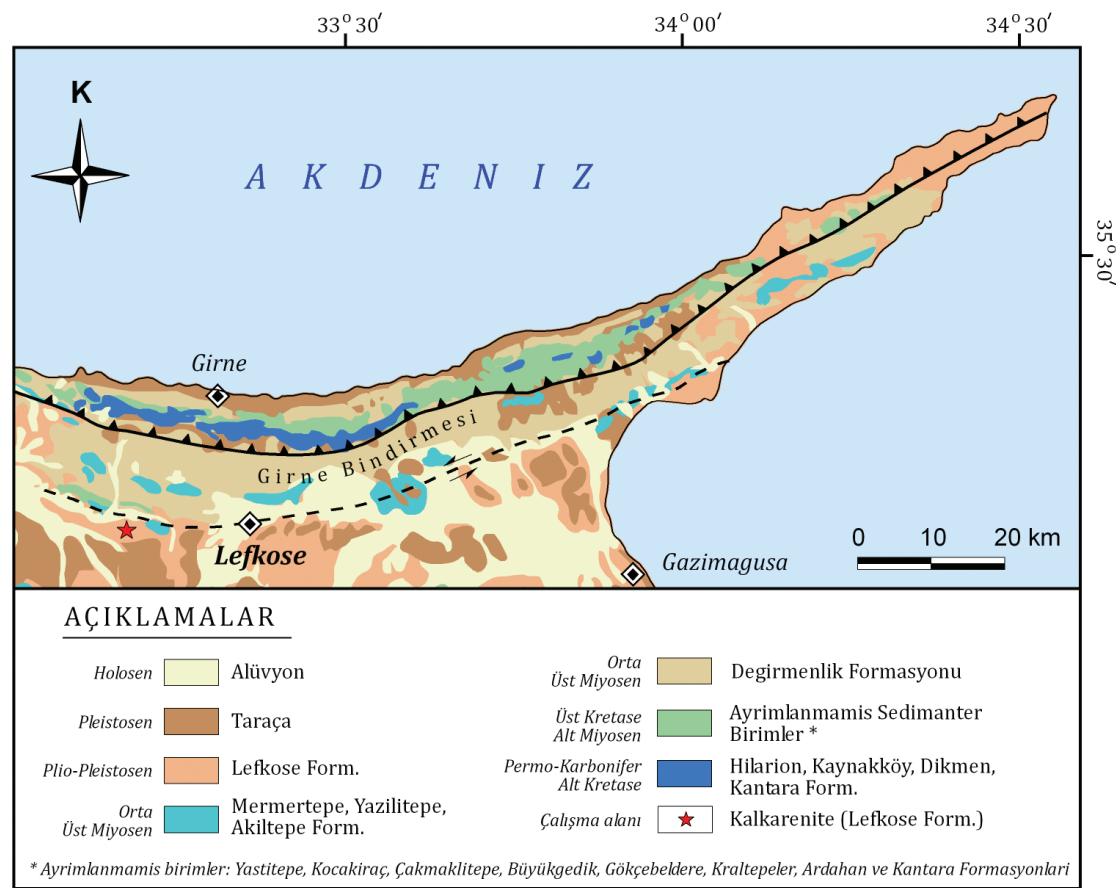

Şekil 2. Kuzey Kıbrıs Türk Cumhuriyeti kuzey-kuzeydoğu kesiminin genelleştirilmiş jeoloji haritası (Hakyemez, 2014'ten değiştirilerek).

Figure 2. Generalized geological map of the north-northeastern part of the Turkish Republic of Northern Cyprus (Modified from Hakyemez, 2014).

\section{MATERYAL VE METOT}

\section{Laboratuvar Deneyleri}

Çalışma kapsamında taş ocakları içinde kurulmuş fabrikalardan temin edilen düzenli geometriye sahip 10 adet bloktan $(15 \times 20 \times 10$ $\mathrm{cm})$ disk örnekler alınarak kayaçların indeks ve dayanım özelliklerini belirlemek amacıyla jeomekanik deneyler yapılmıştır. Bu amaçla, boy/ çap oranı 1'e yakın 50-60 mm çapında diskler oluşturulmuş, termal 1sıtma öncesi ve sonrası bu disklerin boyuna dalga hızı, yoğunluk, ağırlık kaybı ve çekme dayanımları belirlenmiştir. İlksel örneklerin tek eksenli sıkışma dayanımları ise boy/çap oranı 2.5 olan NX çaplı örnekler üzerinde yapılan deneyler sonucunda belirlenmiştir. Tüm deneyler ISRM (2007) tarafindan önerilen standartlara uygun olarak yapılmıştır. Örnek sayıları ve boyutları Çizelge 2'de özetlenmiştir. $\mathrm{Bu}$ deneylere ek olarak ASTM (2016) standartlarında verilen yöntem esas alınarak suda dağılmaya karşı duraylılık deneyleri yapılmış ve deney sonrası kütle değişimleri belirlenerek "suda dağılmaya karşı duraylılık indisi (SDI)" değeri hesaplanmıştır. İlgili standartlar deneyin iki çevrim olarak uygulanmasını önermiş olmakla birlikte, bazı araştırmacılar ikinci çevrim sonunda kayaçların parçalanmış olmalarına rağmen yüksek SDI değerleri vermesinden yola çıkarak özellikle killi ve/veya zayıf çimentolu kayaçlar için en az 4 çevrim önermişlerdir (Koncagül ve Santi, 1999; Gökçeoğlu vd., 2000). Bu nedenle bu çalışma kapmasında deney 4 çevrim olarak uygulanmıştır. 
Atalar, Ersoy, Karahan, Sünnetci

Çizelge 2. Çalışmada kullanılan örnek boyutları ve sayıları.

Table 2. Size and number of the samples used in this study.

\begin{tabular}{|c|c|c|c|c|c|c|c|c|}
\hline \multirow{2}{*}{$\begin{array}{l}\text { Fiziksel ve } \\
\text { mekanik } \\
\text { özellikler }\end{array}$} & \multicolumn{7}{|c|}{$\begin{array}{c}\text { Farklı sıcaklıklar }\left({ }^{\circ} \mathrm{C}\right) \text { için } \\
\text { örnek sayısı }\end{array}$} & \multirow[t]{2}{*}{ Örnek boyutu } \\
\hline & 25 & 105 & 200 & 400 & 600 & 800 & 1000 & \\
\hline SEM & 2 & - & - & - & 2 & - & 2 & $\begin{array}{l}1 \mathrm{~cm}^{3} \\
\text { blok örnek }\end{array}$ \\
\hline $\begin{array}{l}\text { Tek eksenli } \\
\text { s1kışma } \\
\text { dayanımı }\end{array}$ & 5 & - & - & - & - & - & - & $\begin{array}{l}\mathrm{NX} \text { çap } \\
\text { boy/çap }=2.5 / 1\end{array}$ \\
\hline $\begin{array}{l}\text { Çekme } \\
\text { dayanımı }\end{array}$ & 5 & 5 & 5 & 5 & 5 & 5 & 5 & $\begin{array}{l}50-60 \text { mm çap } \\
\text { boy/çap =1/1 }\end{array}$ \\
\hline Yoğunluk & 5 & 5 & 5 & 5 & 5 & 5 & 5 & \\
\hline Porozite & 5 & 5 & 5 & 5 & 5 & 5 & 5 & \\
\hline P-dalga hızı & 5 & 5 & 5 & 5 & 5 & 5 & 5 & \\
\hline
\end{tabular}

\section{Termal Isıtma/Soğutma Uygulaması}

Kapalı ve/veya açık alanda başlayan bir yangın, oksijen miktarına ve yanan malzeme tipine bağlı olarak çok kısa zamanda büyür ve sürekli yayılır. Yangın sırasında sıcaklık lineer olarak artmaz. Sicaklık ilk beş dakikada $500^{\circ} \mathrm{C}^{\prime}$ ye, 30 dakika sonra yaklaşık $800{ }^{\circ} \mathrm{C}^{\prime}$ ye çıkar. Bundan sonra zaman ilerledikçe sıcaklık daha yavaş artar. Bu nedenle yayılım hızının ve şeklinin belirlenmesi amaciyla Eurocode (2012) tarafından yapılan deneylerde farklı yangın tipleri için farklı sıcaklık artış denklemleri önerilmiştir. Bunlar; "Standart Sicaklık-Zaman Eğrisi", "Dış Yangın Eğrisi" ve "Hidrokarbon Eğrisi" olarak genelleştirilmiştir (Şekil 3).

Çalışmada KKTC'nde geniş yayılımlar veren, tarihten günümüze kadar halen diş kaplama olarak sıklıkla kullanılan kalkarenitler kullanılmış, artan sıcaklığa bağlı olarak kayaçların fiziksel ve dayanım özelliklerindeki değişimin araştırılması için örnekler bir kül fırını (UTD-1462) içerisinde 105 ile $1000{ }^{\circ} \mathrm{C}$ arasında $\left(105,200,400,600,800\right.$ ve $\left.1000^{\circ} \mathrm{C}\right)$ değişen sıcaklıklara tabi tutulmuştur. Hedef sicaklığa ulaşıldıktan sonra örnekler bu sicaklıkta 120 dakika süre ile bekletilmiş, deney sonunda oda sıcaklığında soğumaya bırakılmıştır. Çalışmada gerçek yangın etkisini doğru olarak yansıtmak için Eurocode (2012) tarafindan önerilen "Standart Sicaklık-Zaman Eğrisi”ne ait Eşitlik 1 kullanılmıştır.

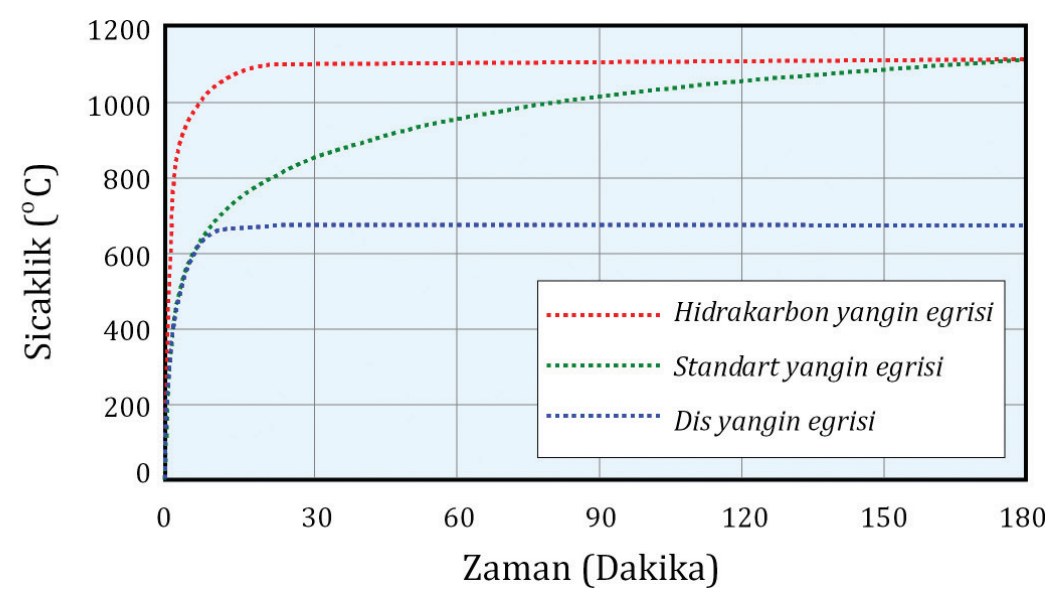

Şekil 3. Eurocode (2012) tarafından önerilen farklı sıcaklık-zaman eğrileri.

Figure 3. Different temperature-time curves proposed by Eurocode (2012). 
$\mathrm{Q}_{\mathrm{s}}=20+345 \log (8 \mathrm{t}+1)$

Burada;

$\mathrm{Q}_{\mathrm{s}}\left({ }^{\circ} \mathrm{C}\right)$ : yangın oluşan alanda ortam sicaklığ 1

$\mathrm{t}$ (dak.): hedef sıcaklığa ulaşmak için gerekli süre

\section{INDEKS VE DAYANIM ÖZELLİKLERİNDEKİ DEĞİŞIMLER}

Sıcaklık etkisinde kayaç özelliklerinde meydana gelecek değişimlerin belirlenmesi amacıyla ilk olarak taze kayaçların indeks ve dayanım özellikleri belirlenmiştir (Çizelge 3). Literatürde düşük dayanımlı kayaçların jeo-mekanik özelliklerinin yüksek sıcaklıklar etkisindeki değişimleri üzerine odaklanan birçok çalışmada çekme dayanımı ve tek eksenli sıkışma dayanımı birlikte değerlendirilirken (Sengun, 2014; Tian vd., 2016; Liv vd., 2019), standartlara uygun örnek teminindeki zorluklar nedeniyle bazı çalışmalarda ise sadece çekme dayanımı tercih edilmiştir (Sirdesai vd., 2017). $\mathrm{Bu}$ çalışmada ise örneklerin tek eksenli sıkışma dayanımı değerlerinin ve SDI değerlerinin belirlenmesi taze örnekler için bir sınıflama yapmak amacıyla gerçekleştirilmiş, sicaklık artışına bağlı olarak dayanımdaki değişimlerin ortaya koyulması amacıyla çekme dayanımı değerleri kullanılmıştır.
Yapılan deneyler sonucunda kalkarenitlerin tek eksenli sıkışma ve çekme dayanımlarının ortalamasının $22 \mathrm{MPa}$ ve $2.50 \mathrm{MPa}$ olduğu belirlenmiştir. Buna ek olarak, 4. çevrim SDI değerinin 84.78, görünür porozite değeri ortalamasının \%37.9 olduğu görülmüştür. Yüksek porozite değerine sahip bu karbonat kayaçların ISRM (2007)'ye göre "zayıf kaya", Gamble (1971)'e göre “düşük duraylı” sınıfında olduğu ortaya koyulmuştur.

Çalışmada kayaçlar $1000^{\circ} \mathrm{C}^{\prime} y e$ kadar "Standart Sicaklık-Zaman Eğrisi”ne ait eşitlik dikkate alınarak ısıtılmış, 2 saat süreyle hedef sıcaklıklara maruz bırakılmıştır. Termal ısıtma sırasında örneklerde ağırlık kaybı ve yoğunluk değerleri ilk $600^{\circ} \mathrm{C}$ 'de neredeyse hiç değişmemiş, $600^{\circ} \mathrm{C}$ 'den sonra ise her iki değerde de ani bir değişim gözlenmiştir. ${ }^{\circ} \mathrm{C}$ sıcaklıkta yoğunluk 1 'in altına düşerken, ağırlık kaybı \%45'e ulaşmıştır. Boyuna dalga hızı değerlerinde hızlı bir azalma meydana gelmiş $800^{\circ} \mathrm{C}$ 'de ise bu azalma \%80'e ulaşmıştır. Çekme dayanımı değerleri ise her sıcaklık kademesinde azalmış, $800^{\circ} \mathrm{C}$ sicaklıkta ilksel değere göre \% 80 oranında bir azalma kaydedilmiştir (Çizelge 4, Şekil 4).

Çizelge 3. Çalışmada kullanılan kalkarenitlerin bazı fiziksel ve dayanım özellikleri.

Table 3. Some physical and strength properties of the calcarenites used in this study.

\begin{tabular}{ccc|ccc|ccc|ccc|ccc}
\hline & \multicolumn{3}{c|}{$\begin{array}{c}\text { Yoğunluk } \\
\left(\mathrm{g} / \mathrm{cm}^{3}\right)\end{array}$} & \multicolumn{3}{c|}{$\begin{array}{c}\text { Etkili Porozite } \\
(\%)\end{array}$} & \multicolumn{2}{c|}{ Çekme dayanımı (MPa) } & \multicolumn{2}{c|}{$\begin{array}{c}\text { Tek eksenli sıkışma } \\
\text { dayanımı }(\mathrm{MPa})\end{array}$} & \multicolumn{2}{c}{$\begin{array}{c}\text { P-dalga hızı } \\
(\mathrm{m} / \mathrm{s})\end{array}$} \\
\hline Mak & Min & Ort & Mak & Min & Ort & Mak & Min & Ort & Mak & Min & Ort & Mak & Min & Ort \\
\hline 1.75 & 1.60 & 1.66 & 40.7 & 32.6 & 37.9 & 2.55 & 2.48 & 2.50 & 25 & 19 & 22 & 4100 & 3700 & 3795 \\
\hline
\end{tabular}


Atalar, Ersoy, Karahan, Sünnetci

Çizelge 4. İki saat süre ile yüksek sıcaklıklara maruz bırakılan kalkarenitlerin indeks ve dayanım özelliklerindeki değişimler.

Table 4. Changes of the index and strength properties of the calcarenites exposed to high temperature values for two hours.

\begin{tabular}{|c|c|c|c|c|c|c|c|c|c|c|c|c|}
\hline \multirow[t]{2}{*}{$\begin{array}{l}\text { Sicaklik } \\
\left({ }^{\circ} \mathrm{C}\right)\end{array}$} & \multicolumn{3}{|c|}{$\begin{array}{c}\text { Yoğunluk } \\
\left(\mathrm{g} / \mathrm{cm}^{3}\right)\end{array}$} & \multicolumn{3}{|c|}{$\begin{array}{c}\text { Ağırlık kaybı } \\
(\%)\end{array}$} & \multicolumn{3}{|c|}{$\begin{array}{l}\text { P-dalga hizı } \\
(\mathrm{m} / \mathrm{s})\end{array}$} & \multicolumn{3}{|c|}{ Çekme dayanımı (MPa) } \\
\hline & Mak. & Min. & Ort. & Mak. & Min. & Ort. & Mak. & Min. & Ort. & Mak. & Min. & Ort. \\
\hline 25 & 1.75 & 1.60 & 1.66 & - & - & - & 4100 & 3700 & 3795 & 2.55 & 2.48 & 2.50 \\
\hline 105 & 1.77 & 1.61 & 1.66 & - & - & - & 4042 & 3672 & 3787 & 2.90 & 1.70 & 2.30 \\
\hline 200 & 1.70 & 1.60 & 1.65 & - & - & - & 3757 & 3484 & 3581 & 2.02 & 1.72 & 1.91 \\
\hline 400 & 1.69 & 1.62 & 1.67 & 0.12 & 0.23 & 0.15 & 3186 & 2885 & 3067 & 1.69 & 1.60 & 1.63 \\
\hline 600 & 1.67 & 1.60 & 1.62 & 0.86 & 1.60 & 1.06 & 2332 & 2193 & 2268 & 0.61 & 0.55 & 0.57 \\
\hline 800 & 1.52 & 1.44 & 1.47 & 7.10 & 11.2 & 9.60 & 698 & 620 & 665 & 0.58 & 0.50 & 0.53 \\
\hline 1000 & 0.95 & 0.92 & 0.94 & 38.6 & 44.5 & 41.2 & - & - & - & - & - & - \\
\hline
\end{tabular}
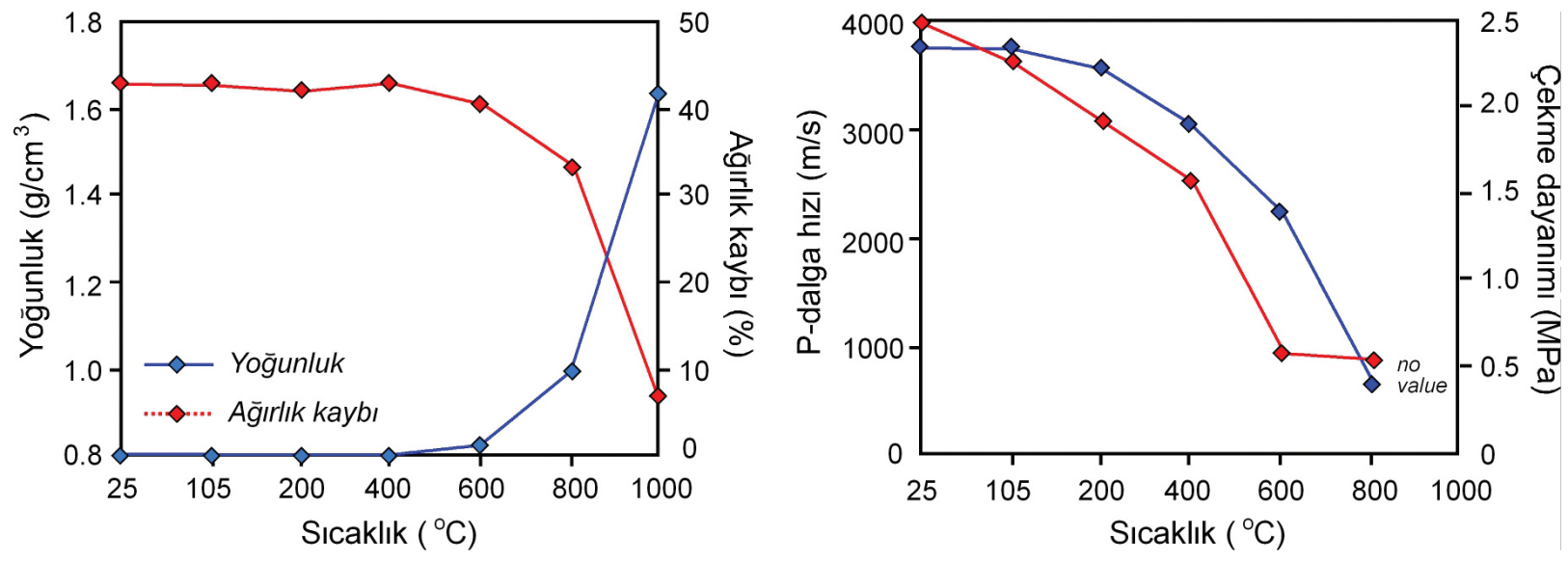

Şekil 4. Yüksek sıcaklıklara bağlı olarak kalkarenitlerin indeks ve dayanım özelliklerindeki değişimler.

Figure 4. The changes in the physical and strength properties of the calcarenites depending on high temperatures.

Yüksek sıcaklıkların özellikle magmatik kayaçların fiziksel ve dayanım özellikleri üzerindeki etkisinin araştırıldı ğ birçok çalışmada porozite, birim hacim ağırlık ve yoğunluk gibi fiziksel özellikler ile, elastisite modülü, tek eksenli sıkışma ve çekme dayanımı gibi mekanik özelliklerin artan sıcaklığa bağlı olarak sürekli azaldığı belirtilmiştir (Mao vd., 2009: Zhang vd., 2016: Yang vd., 2019: Ersoy vd., 2019: Liu vd., 2020). Bununla birlikte, özellikle kil içeriğine ve tane boyutuna bağlı olarak yüksek sıcaklıklara maruz kalan karbonatlı kayaçlarda
2 farklı davranış gözlenmiştir. Bunlar aşağıdaki gibi sıralanabilir (Ersoy vd., 2021a):

(1) Kil içeriği yüksek düşük dayanımlı kayaçlarda dayanım belirli bir sıcaklığa kadar artmış veya sabit kalmış, daha sonra sıcaklık artışına bağlı olarak ani bir düşüş göstermiştir (Ferrero vd., 2001; Mao vd., 2009; Sengun, 2014; Ozguven ve Ozcelik, 2014; (Ersoy vd., 2021b).

(2) Kil içeriği az olan düşük dayanımlı kayaçlarda ise dayanım sürekli azalmıştır (Brotons vd., 2013; Crosby vd., 2018). 
Çalışma konusu kalkarenitler kum boyutlu tanelerden oluşan karbonatlı kayaçlardır ve literatüre uygun olarak kil içeriği düşük olan bu kayaçlarda artan sıcaklığa bağlı olarak dayanım sürekli olarak azalmıştır.

Karbonatlı kayaçlar dışında yüksek sıcaklıklar etkisinde ağırlık kaybının bu denli arttığ1 ve yoğunluğun aynı ölçüde azaldığ 1 kayaç grubu mevcut değildir. Çünkü karbonatlı kayaçlar termal bozunumu sırasında, ayrışma sıcaklığına ulaşıncaya kadar, tanecik yapısında bazı fiziksel değişimler meydana gelmekte, öncelikle maddenin yüzey nemi uzaklaşmakta, sıcaklığın yükselmesiyle az miktardaki organik madde yanmakta ve termal bozunma sırasında karbondioksit gazı açığa çıkmaktadır. Buna bağlı olarak karbonatlı kayaçlar termal bozunma sonucu kütlelerinin yaklaşık \%4045'1nı kaybetmekte ve taneciğin dış şekli önemli ölçüde değişmediğinden yoğunluğu azalmakta ve gözenekliliği artmaktadır (Moropoulou vd., 2001; Okonkwo ve Adefila, 2012). Bu çalışmada da bu durum net olarak görülmüştür.
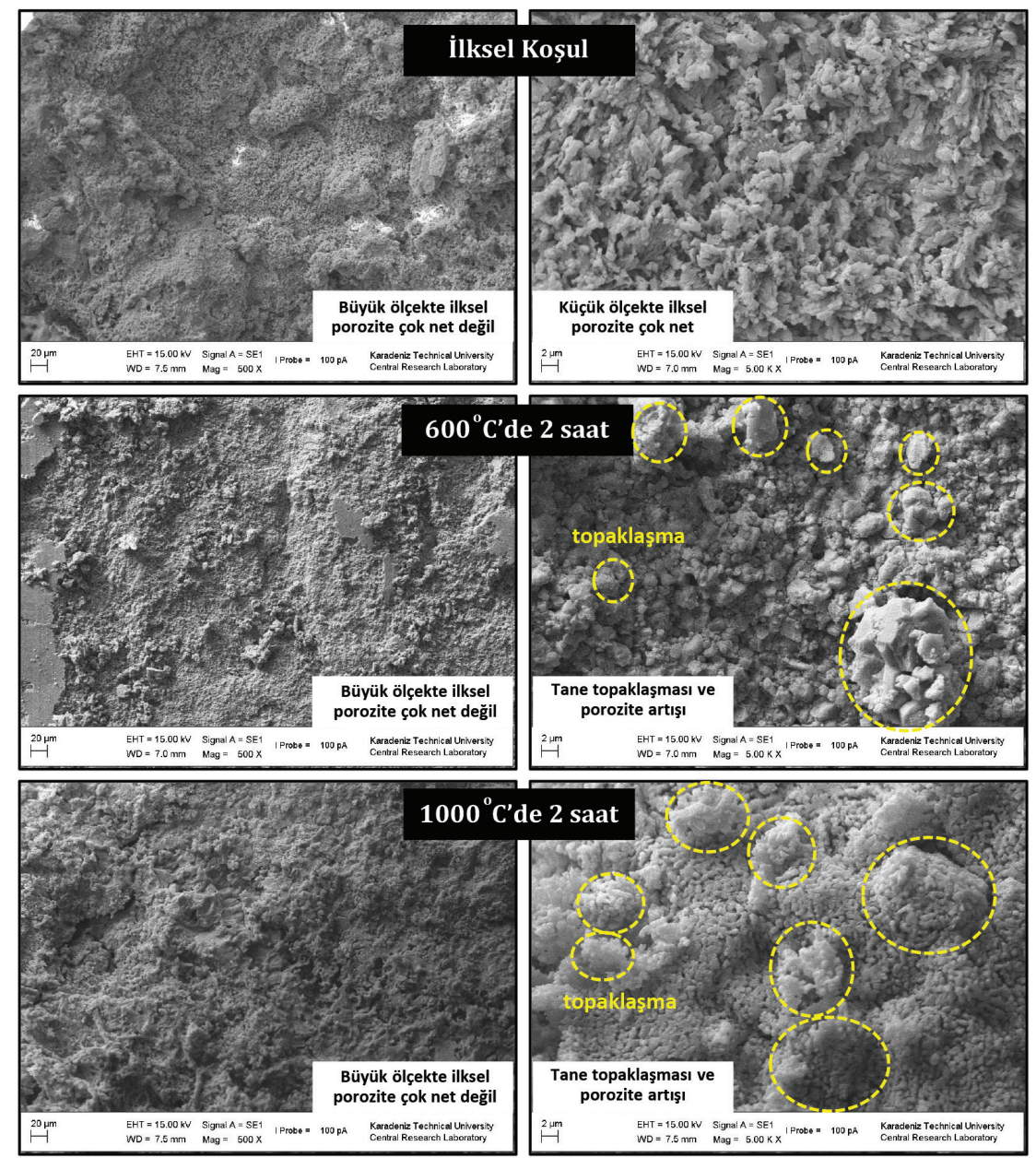

Şekil 5. İlksel durum ve yüksek sıcaklıklara maruz kalan kalkarenitlere ait SEM görüntüleri (Ersoy vd., 2021a).

Figure 5. SEM images of the calcarenites for the initial conditions and high temperature treatments (Ersoy vd., 2021a). 
Atalar, Ersoy, Karahan, Sünnetci

\section{MİKRO-YAPISAL ÖZELLIKKLERDEKİ DEĞíşìM}

Çalışma kapsamında yüksek sıcaklık etkisinde kalan kayaçlarda meydana gelen mikroyapısal değişikliklerin belirlenmesi amacıyla SEM çekimleri gerçekleştirilmiştir. Analizler ilksel durum, $600^{\circ} \mathrm{C}$ ve $1000^{\circ} \mathrm{C}$ sicakliklara maruz kalan örnekler üzerinde uygulanmıştır. İlksel durumda kalkarenitlerde granüler yapı SEM görüntülerinde (5000x) net olarak görülmektedir. Ancak sıcaklık artışına bağlı olarak özellikle $600^{\circ} \mathrm{C}$ sicaklıklarda mineral topaklanması dikkat çekmektedir. $1000^{\circ} \mathrm{C}$ sicaklıkta ise kalsinasyon sürecine bağlı olarak kısmi ergime ve topaklaşma olayı artarak devam etmiştir (Şekil 5). Bu durum tane boyutunun artmasına, mikro süreksizliklerin oluşmasına, porozitenin artmasına ve buna bağlı olarak dayanımın sürekli azalmasına neden olmuştur.

\section{SONUÇLAR}

$\mathrm{Bu}$ çalışma kapsamında düşük dayanımlı karbonat kökenli kumtaşlarının (kalkarenit) 200$1000^{\circ} \mathrm{C}$ arasındaki yüksek sıcaklıklara maruz kaldıktan sonra mühendislik davranışındaki değişimler araştırılmıştır. Çalışmada gerçek bir yangına ait sıcaklık-zaman eğrisini temsil etmek amaciyla Eurocode (2012) tarafindan önerilen üstel denklem kullanılmış, örnekler hedeflenen sıcaklıklarda 2 saat süre ile tutulmuştur. Isınma sürecinden sonra örnekler oda sicaklığında soğumaya bırakılmıştır.

Büyük kristalli kireçtaşlarında veya karbonat kumtaşlarında, ince taneli veya kristalli karbonat kayaçların aksine, sıcaklığın kristal tanelerinde kırılmaya neden olan bir gerilim oluşturduğu ve bu nedenle yapının bütünlügünün bozulduğu bilinmektedir (Kurt, 2010). Termal 1sitma sonrasında ilk $600{ }^{\circ} \mathrm{C}$ sıcaklığa kadar kayaçların yoğunluk ve ağırlık kaybı değerlerinde önemli bir değişim olmazken çekme dayanımının \% 40 oranında azalması bu sürecin bir ürünüdür. Kalsinasyon olarak bilinen bu süreç genleşmeye ve mikro gözeneklerin oluşmasına neden olmaktadır. Bu durum SEM görüntülerinde net olarak gözlenmiş, özellikle $600^{\circ} \mathrm{C}$ 'den sonra ağırlık kaybı başlamış, yoğunluk, boyuna dalga hızı ve çekme dayanımı değerlerinde çok net bir azalma gözlenmiştir. $800^{\circ} \mathrm{C}$ 'den sonra ise tüm değerlerde ani değişim görülmüş, yoğunluk değerlerinde yaklaşık \%50'lik azalma, boyuna dalga hızı değeri ve çekme dayanımı \%80 oranında azalma kaydedilmiştir.

Bilindiği gibi bina dişında meydana gelebilecek bir yangının sicaklığ 680 dereceyi geçmezken kapalı ortamda sicaklık 1000 dereceyi aşmaktadır (Eurocode 2012, Şekil 3). Elde edilen sonuçlar; KKTC'nde yapı taşı olarak yaygın şekilde kullanılan kalkarenitlerin bir dış yangın etkisinde mühendislik özelliklerini büyük ölçüde koruyacağını, iç yangın durumunda ise dayanımlarını çok büyük ölçüde kaybedeceğini göstermektedir. $\mathrm{Bu}$ nedenle yangın tehlikesinin daha fazla olduğu inşaat yapılarında bu kayaçların, ilgili diğer deneylerin yapılması koşulu ile sadece dış kaplama olarak değerlendirilmesi önerilmektedir. Ayrıca bu kayaçlardan inşa edilmiş bir yapıda meydana gelecek iç yangın sonrası ise yapıda büyük hasar oluşabileceği durumu göz ardı edilmemelidir.

\section{KAYNAKLAR}

ASTM D4644-16, 2016. Standard Test Method for Slake Durability of Shales and Other Similar Weak Rocks, ASTM International, West Conshohocken, PA.

Brotons, V., Tomas, R., Ivorra, S., Alarcon, J.C., 2013. Temperature influence on physical and mechanical properties of a porous rock: San 
Julian's calcarenite. Engineering Geology, 167, 117-127.

Crosby, Z.K., Gullet, P.M., Akers, S.A., Graham, S.S., 2018. Characterization of mechanical behavior of slam limestone containing thermally induced microcracks. International Journal of Rock Mechanics and Mining Sciences, 101, 54-62.

Dong, Z., Sun, Q., Ye, J., Zhang, W., 2019. Changes in color and roughness of red sandstone at high temperatures. Bulletin of Engineering Geology and the Environment, https://doi.org/10.1007/ s10064-019-01678-w.

Ersoy, H., Kolaylı, H., Karahan, M., Harputlu Karahan, H., Sünnetci, M.O., 2019. Effect of thermal damage on mineralogical and strength properties of basic volcanic rocks exposed to high temperatures. Bulletin of Engineering Geology and the Environment, 78, 1515-1525.

Ersoy, H., Atalar, C., Sünnetci, M.O., Kolayl1, H., Karahan, M., Firat Ersoy, A., 2021a. Assessment of damage on geo-mechanical and micro-structural properties of weak calcareous rocks exposed to fires using thermal treatment coefficient. Engineering Geology, 284, 1-13.

Ersoy, H., Karahan, M., Kolaylı, H., Sünnetci, M.O., 2021b. Influence of mineralogical and microstructural changes on the physical and strength properties of post-thermal-treatment clayey rocks. Rock Mechanics and Rock Engineering, 54, 679-694.

Ferrero, A.M., Marini, P., 2001. Technical note: Experimental studies on the mechanical behaviour of two thermal cracked marbles. Rock Mechanics and Rock Engineering, 34, 57-66.

Gökçeoğlu C., Ulusay R., Sönmez H., 2000. Factors affecting the durability of selected weak and clay-bearing rocks from Turkey, with particular emphasis on the influence of the number of drying and wetting cycles. Engineering Geology, $57,215-237$.

Hakyemez, H.Y., 2014. Kuzey Kıbrıs'in temel jeolojik özellikleri. TPJD Bülteni, 26(2), 7-46.

ISRM. 2007. The complete ISRM suggested methods for rock characterization, testing and monitoring:
1974-2006. Suggested methods prepared by the commission on testing methods, International Society for Rock Mechanics. In: Ulusay R, Hudson JA (eds) Compilation arranged by the ISRM Turkish National Group.

Kilıç, E., 2006. The influence of high temperatures on limestone P-wave velocity and Schmidt hammer strength. International Journal of Rock Mechanics and Mining Sciences, 43, 980-986.

Koca, M.Y., Ozden, G., Yavuz, A.B., Kincal, C., Onargan, T., Kucuk, K., 2006. Changes in the engineering properties of marble in fireexposed columns. International Journal of Rock Mechanics and Mining Sciences, 43, 520-530.

Koncagul E.C., Santi P.M., 1999. Predicting the unconfined compressive strength of the Breathitt shale using slake durability, Shore hardness and rock structural properties. International Journal of Rock Mechanics and Minining Science, 36, 139-153.

Liu, S., Xu, J., 2015. An experimental study on the physico-mechanical properties of two post-hightemperature rocks. Engineering Geology, 185, 63-70.

Liu, Z., Yao, Q., Kong, B., Yin, J., 2020. Macro-micro mechanical properties of building sandstone under different thermal damage conditions and thermal stability evaluation using acoustic emission technology. Construction and Building Materials, 246, 118485.

Mao, X.B., Zhang, L.Y., Li, T.Z., Liu, H.S., 2009. Properties of failure mode and thermal damage for limestone at high temperature. International Journal of Mining Science and Technology, 19, 290-294.

Meng, Q.B., Wang, C.K., Liu, J.F., Zhang, M.W., Lu, M.M., Wu, Y., 2020. Physical and microstructural characteristics of limestone after high temperature exposure. Bulletin of Engineering Geology and Environment, 79, 1259-1274.

Ozguven, A., Ozcelik, Y., 2013. Investigation of some property changes of natural building stones exposed to fire. Construction and Building Materials, 38, 813-821. 
Atalar, Ersoy, Karahan, Sünnetci

Qin, Y., Tian, H., Xu, N.X, Chen, Y., 2019. Physical and mechanical properties of granite after hightemperature treatment. Rock Mechanics and Rock Engineering, 53, 305-322.

Sengun, N., 2014. Influence of the thermal damage on physical and mechanical properties of carbonate rocks. Arabian Journal of Geosciences, 7, 55435551.

Sirdesai, N. N., Singh, T. N., Ranjith, P. G., Singh, R., 2017. Effect of varied durations of thermal treatment on the tensile strength of red sandstone. Rock Mechanics and Rock Engineering, 50, 205213.

Sun, Q., Lu, C., Cao, L., 2016. Thermal properties of sandstone after treatment at high temperature. International Journal of Rock Mechanics and Mining Sciences, 85, 60-66.

Tian, H., Kempka, T., Yu, S., Ziegler, M., 2016. Mechanical properties of sandstones exposed to high temperature. Rock Mechanics and Rock Engineering, 49, 321-327.

Wang, P., Xu, J., Liu, S., Wang, H., 2016. Dynamic mechanical properties and deterioration of red sandstone subjected to repeated thermal shocks. Engineering Geology, 212, 44-52.
Wang, P., Xu, J., Liu, S., 2015. Staged Moduli: A quantitative method to analyze the complete compressive stress-strain response for thermally damaged rock. Rock Mechanics and Rock Engineering, 48, 1505-1514.

Yang, J., Yun Fu, L., Zhang, W., Wang, Z., 2019. Mechanical propert and thermal damage factor of limestone at high temperature. International Journal of Rock Mechanics and Mining Sciences, 117, 11-19.

Yavuz, H., Demirdag, S., Caran, S., 2010. Thermal effect on the physical properties of carbonate rocks. International Journal of Rock Mechanics and Mining Sciences, 47, 94-103.

Zhang, L., Mao, X., Liu, R., 2014. Meso-structure and fracture mechanism of mudstone at high temperature. International Journal of Mining Science and Technology, 24, 433-439.

Zhang, W., Sun, Q., Hao, S., Wang, B., 2016. Experimental study on the thermal damage characteristics of limestone and underlying mechanism. Rock Mechanics and Rock Engineering, 49, 2999-3008. 